\title{
INSEGURANÇA, PROTEÇÃO VICINAL E CONTROLE SOCIAL NAS CIDADES BRASILEIRAS $^{1}$
}

Fillipi Lúcio Nascimento

Mestrando do Programa de Pós-Graduação em Sociologia da Universidade Federal de Alagoas.

\section{RESUMO}

$\mathrm{O}$ artigo discute a percepção da insegurança expressa pelos moradores de bairros das cidades de Maceió (AL), do Rio de Janeiro (RJ) e de Belo Horizonte (MG) e os respectivos mecanismos comunitários de proteção implementados visando o gerenciamento do dilema. A pesquisa compara três estudos de caso a partir do emprego de técnicas qualitativas. O trabalho de campo foi realizado entre os meses de março de 2016 e dezembro de 2017. Os bairros foram selecionados a partir de critérios de dissimilaridade a fim de refletir sobre as diferentes realidades urbanas que existem atualmente no Brasil. A despeito dos diferentes contextos sobre os quais estão situados os bairros analisados neste estudo, em ambos os casos pôdese verificar características comuns que permitiram aproximar as percepções sobre a insegurança e as visões sobre o provimento da segurança, que por vezes contradizem a própria convivência democrática nas cidades.

Palavras-chave: Medo do crime. Percepção da insegurança. Eficácia coletiva. Efeito de vizinhança. Mecanismos comunitários de proteção.

\section{INTRODUÇÃO}

A vida nos centros urbanos é marcada pela insegurança. A percepção dessa insegurança motiva a população a desenvolver os mais diversos mecanismos de proteção. Esses mecanismos compreendem práticas que partem da iniciativa privada, como a construção de obstáculos e fortificações, a instalação de câmeras de vigilância ou a

\footnotetext{
1 Artigo apresentado sob o título de "Insegurança e mecanismos comunitários de proteção nas cidades brasileiras" no GT "Produção do medo, percepções de insegurança e política criminal" do Seminário Internacional Insegurança e Punitividade na América Latina, coordenado pelos professores doutores Emerson do Nascimento (Instituto de Ciências Sociais, Universidade Federal de Alagoas), Hugo Leonardo Santos (Faculdade de Direito, Universidade Federal de Alagoas) e Henrique Carvalho (Warwick University, Inglaterra).
} 
contratação de serviços personalizados de segurança; ou de iniciativas coletivas, como a formação de associações comunitárias de vigilância, entre outras.

Segundo o Projeto de Opinião Pública da América Latina (LAPOP, na sigla em inglês), o Brasil registra uma das mais altas taxas de percepção da insegurança no continente, superado somente pela Venezuela e pelo Peru. Essa percepção está relacionada ao medo que decorre do crime (homicídios, roubos, estupros, etc.) e da desordem social (consumo de drogas em vias públicas, pichações, consumo abusivo de álcool, etc.). Esses fenômenos são tradicionalmente estudados sob diferentes perspectivas: de um lado, as pesquisas que analisam o medo do crime têm contribuído na identificação de seus principais componentes, dentre os quais, a vitimização, a confiança nas autoridades, a influência das estruturas urbanas e do contexto econômico; por outro lado, as pesquisas que têm a desordem social por objeto tendem a defini-la como um produto da incapacidade comunitária de manter efetivamente o controle social sobre seus residentes. Essa noção, situada no campo da Ecologia Humana, enfatiza o espaço como variável explicativa das interações sociais na cidade.

Este artigo discute a percepção da insegurança expressa pelos moradores de bairros das cidades de Maceió (AL), do Rio de Janeiro (RJ) e de Belo Horizonte (MG) e os respectivos mecanismos comunitários de proteção implementados visando o gerenciamento do dilema. A despeito dos diferentes contextos sobre os quais estão situados os bairros selecionados neste estudo, em ambos os casos pôde-se verificar características comuns que permitiram aproximar as percepções sobre a insegurança e as visões sobre o provimento da segurança, que por vezes contradizem a própria convivência democrática nas cidades.

\section{MEDO, INSEGURANÇA E PROTEÇÃO: CONTEXTO TEÓRICO DA DISCUSSÃO}

A segurança tem sido estudada a partir de perspectivas teóricas que enfatizam distintos elementos, como os tipos de segurança relacionados ao crime (segurança pública), às leis (segurança jurídica), à saúde (segurança sanitária), entre outros. Em termos gerais, a segurança pode ser contextualizada pela ausência de ameaças ou pela neutralização de ameaças (BAUMAN, 2008). O que aqui se define por "ameaça" é todo e qualquer fator que potencialmente compromete a integridade física, simbólica ou psíquica de pessoas, seres ou coisas. Ameaças geram medo. "porque uma ameaça [...], independente de sua forma, normalmente produz duas sensações poderosas. Uma é o medo [...]. A outra é uma sensação de que a desgraça é personificada, a sensação de que a força hostil, qualquer que seja sua 
manifestação específica, possui vontade" (TUAN, 2005, p. 13-14). O medo é uma emoção complexa produzida em função de circunstâncias externas (exceto nos casos patológicos) definidas como "ameaçadoras". Nesse sentido, as ameaças parecem constituir as matrizes do provimento da segurança, da percepção da insegurança e da geração de medo.

Mobilizados em torno da compreensão do convívio nos espaços urbanos, esses conceitos permitem caracterizar como "seguros" aqueles contextos nos quais os indivíduos estão conscientes de que sua integridade física (ou psíquica) será preservada. Nesses espaços, eles se sentem à vontade para estar ou transitar sem incorrer na possibilidade de um roubo ou de uma agressão violenta, dentre outras ameaças as quais estariam sujeitos em espaços caracterizados como "inseguros".

O medo do crime, dentre várias outras possibilidades de interpretação, pode ser entendido como uma reação emocional de temor gerada a partir da identificação de elementos externos que, a partir de experiências coletivas ou individuais, estão associados à criminalidade. Por exemplo: tradicionalmente, ruas escuras ou mal iluminadas estão associadas à possibilidade de roubos. Consolidara-se na consciência coletiva a ideia de que a escuridão ou a baixa visibilidade não apenas facilita a ação do criminoso (no sentido de tornar mais oportuna sua abordagem ou fuga), como também cerceia as possibilidades de sua identificação, o que, em última instância, acarretaria na sua apreensão (gera impunidade) (AVER, 2013). Nesses termos, o medo do crime seria, basicamente, uma resposta a elementos percebidos no ambiente.

Mas o medo do crime não é moldado estrita e necessariamente pelas características ambientais. Os elementos que integram o background socioeconômico, a despeito de serem por vezes mobilizados equivocadamente em um tipo de explicação agregada dos eventos delitivos, devem ser considerados enquanto variáveis explicativas do medo do crime. Por exemplo: o tipo de medo que assola moradores de bairros nobres pode ser totalmente distinto do medo nutrido por moradores de bairros periféricos. A forma como cada bairro é percebido se distingue em função daqueles que neles residem e daqueles que neles transitam. Em uma outra perspectiva, o medo do crime pode estar associado a determinados segmentos étnicos: no Brasil, indivíduos negros são mais "criminalizados" que indivíduos não-negros (DE PAULA et al., 2018; BRISOLA, 2012). Uma outra face do problema indica o sexo da vítima como um possível elemento disparador: o medo de um estupro assola preponderantemente mulheres a homens. Nesses casos, eles tendem a ser interpretados por elas como potenciais agressores (CAMPOS et al., 2018). 
Entre as diversas perspectivas teóricas de tratamento do objeto em questão (o medo do crime), os estudos ecológicos, próprios da Escola Sociológica de Chicago, parecem conciliar perspicazmente distintas unidades na compreensão das condições de ocorrência do crime e dos mecanismos criados para a gestão do medo e enfrentamento da insegurança.

Clifford Shaw e Henry McKay (1969), partindo da análise de dados estatísticos sobre a cidade de Chicago das décadas de 1940 a 1960, observaram que os bairros que concentravam as mais altas taxas de criminalidade correspondiam a uma espécie de "perfil": eram bairros pobres e deteriorados, etnicamente heterogêneos e de ampla rotatividade populacional. Essas características, segundo os autores, dificultariam a concepção e o compartilhamento de valores comuns à comunidade, resultando na fragilização da coesão comunitária e, consequentemente, no enfraquecimento dos mecanismos de controle social. Nesse cenário de "desorganização social”, as motivações de alguns membros da coletividade encontrariam um terreno fértil. A prostituição, o consumo de drogas ilegais, o consumo abusivo de álcool, o vandalismo, os episódios de violência e a criminalidade seriam condutas signatárias da desorganização social em uma dada localidade.

Muito embora a teoria da desorganização social estabeleça, a princípio, uma correlação entre as taxas de criminalidade e fatores ambientais e socioeconômicos, essa correlação não se dá de forma direta e simples. As regiões da cidade onde a degradação urbana é acentuada e os moradores são de baixo poder aquisitivo estão mais sujeitas ao crime desde que sejam incapazes de estabelecer limites aos comportamentos desviantes em seu cotidiano. Nesse sentido, mesmo as comunidades mais pauperizadas poderiam apresentar baixos índices de criminalidade, uma vez que demonstrassem um alto grau de eficácia coletiva. Do contrário, onde prevalecesse o medo e a desconfiança entre os moradores, o que indicaria uma baixa eficácia coletiva, a criminalidade cresceria e se consolidaria. Na teoria da desorganização social, o que está em questão é a habilidade coletiva de exercício do controle social.

Robert Sampson e colaboradores (2009) dedicaram-se a compreender os elementos que fortaleceriam ou enfraqueceriam essa disposição comunitária para desempenhar o controle social sobre seus residentes. A partir de pesquisas de vitimização realizadas na cidade de Chicago entre as décadas de 1950 e 1970, Sampson e seus colaboradores verificaram que o grau de confiança, a disponibilidade recíproca entre vizinhos e os valores por eles compartilhados constituiriam indicadores da "eficácia coletiva". O conceito relaciona a coesão e a confiança comunitária sobre o compromisso proativo para intervir na manutenção do controle social. Esse compromisso seria assumido, segundo os autores, a partir de 
situações de medo e ansiedade vivenciadas e compartilhadas pela comunidade, portanto, de uma insegurança coletiva (SAMPSOM et al., 2009, p. 56).

A percepção de insegurança mobiliza a comunidade na criação e gerenciamento dos mais diversos tipos de mecanismos de proteção. ${ }^{2}$ Tratam-se de estratégias individuais ou coletivas, públicas ou privadas, e que têm sido estudadas fundamentalmente em nível de bairro (ZALUAR; RIBEIRO, 2009; ZALUAR, 1999). O bairro deve aqui ser entendido como um agrupamento social primário de onde se desenvolvem sociabilidades e responsabilidades específicas, sustentadas por fronteiras de diferenciação que contêm tanto aspectos objetivos quanto subjetivos, físicos e culturais.

Nas cidades brasileiras, os produtos vicinais mobilizados em detrimento do sentimento de insegurança se expressam principalmente em mecanismos de controle territorial e social. Esse "controle" compreende formas de regulação materializadas em equipamentos de defesa (cercas elétricas, câmeras, portões eletrônicos, etc.) e em instrumentos de gestão do acesso (guaridas, cancelas e catracas), para além das associações público-privadas e das polícias comunitárias. Não obstante, esses dispositivos expressam uma visão de sociedade marcada por uma forte demanda por segurança e por punitividade (DISSENHA; JÚNIOR, 2018).

As principais pesquisas desenvolvidas em torno da temática demonstram que muitos dos mecanismos comunitários de proteção são instituídos na tentativa de corresponder a ineficiência ou a desconfiança no provimento estatal da segurança, e implicam em uma grande capacidade de agência por parte dos vizinhos. Assim, tem-se estudado a dinâmica desses mecanismos em função das características dos serviços policiais.

\section{TRAÇADO METODOLÓGICO}

Esta pesquisa compara três estudos de caso a partir do emprego de técnicas qualitativas: a observação dos bairros e a realização de entrevistas semiestruturadas. O trabalho de campo foi realizado entre os meses de março de 2016 e dezembro de 2017. Os bairros foram selecionados a partir de critérios de dissimilaridade a fim de refletir sobre as

\footnotetext{
2 Aqui há de se distinguir brevemente as noções de "proteção" e "controle", ou "controle social". Todo instrumento de controle social é um mecanismo de proteção, mas nem todo mecanismo de proteção é um instrumento de controle social. Este pressupõe algum tipo de reinserção, de reintegração às normas convencionais. Nem todos os mecanismos de proteção cumprem com esse proposto. Muitos desses mecanismos, do contrário, pressupõem o isolamento, o distanciamento. Vide os processos de condominização e seus efeitos (LEFEBVRE, 2002; 1991; SANTOS, 1993).
} 
diferentes realidades urbanas que existem atualmente no Brasil. ${ }^{3}$ Este estudo explora os mecanismos comunitários de proteção de bairros das cidades do Rio de Janeiro (RJ), Belo Horizonte (MG) e Maceió (AL).

Foram desenvolvidas 238 entrevistas com distintos atores, entre residentes e nãoresidentes (transeuntes) dos bairros de Laranjeiras (Rio de Janeiro), Padre Eustáquio (Belo Horizonte) e Farol (Maceió). As entrevistas foram viabilizadas sem qualquer tipo de contato prévio ou resistência por parte dos entrevistados. A identificação dos entrevistados se realizou seguindo os critérios de amostragem (orientado a coletar informações necessárias para estabelecer comparações de atores, eventos, atividades relevantes e categorias analíticas) e saturação teóricas (que evita coletar informações que não agregam valor ao exame de alguma categoria analítica) (VALLES, 2007).

Uma vez transcritas, a análise dos conteúdos das entrevistas foi feita a partir da "teoria fundada", de Strauss e Corbin (1990), da qual uma análise individual e transversal das categorias definidas desde os polos temáticos permite estabelecer explicações e relações dos diferentes aspectos do fenômeno estudado. Esta pesquisa se apresenta como um estudo comparativo de casos e não tem como pretensão estender as conclusões alçadas à dinâmica de outros bairros em outras cidades brasileiras.

\section{RESULTADOS E DISCUSSÃO}

\subsection{Descrição dos bairros}

$\mathrm{Na}$ cidade do Rio de Janeiro, metrópole brasileira com mais de 6 milhões de habitantes, localiza-se o bairro de Laranjeiras. Situado na Zona Sul da cidade, Laranjeiras é um dos bairros mais antigos, com ocupação iniciada no século XVII, com a construção de chácaras no vale ao redor do Rio Carioca. Atualmente, o bairro abriga o Palácio Guanabara, sede do governo do estado do Rio de Janeiro e o Palácio Laranjeiras, residência oficial do governador do estado. O bairro também sedia o Batalhão de Operações Especiais da Polícia Militar do Estado do Rio de Janeiro (BOPE) e a administração da Força Nacional de

\footnotetext{
${ }^{3}$ Dentro desse sistema coexistem três grupos: as metrópoles (São Paulo, Rio de Janeiro, Salvador e Brasília), que representam menos de $1 \%$ do total dos municípios brasileiros; as cidades intermediárias, que representam aproximadamente 29\%; e as pequenas cidades, que respondem por mais de $70 \%$ (IBGE, 2015).
} 
Segurança. Trata-se de um bairro tipicamente residencial, preponderantemente verticalizado e de classe média alta.

O bairro de Padre Eustáquio é um dos mais tradicionais da capital mineira, Belo Horizonte. Localizado na região Noroeste da cidade, teve sua formação a partir da junção de várias vilas: a Vila Progresso, a Vila Celeste Império, a Vila Santa Rita e a Vila Futura, todas datadas da década de 1920. É caracterizado pelos residentes como um "bairro de periferia" a despeito de suas condições infraestruturais (ruas pavimentadas e iluminadas, redes de esgotamento subterrâneo, espaços públicos em bom estado de conservação e serviços regulares de limpeza urbana) e do alto IDH (Índice de Desenvolvimento Humano), de 0,800 pontos, características que o situam na categoria de bairro de classe média.

O bairro do Farol está localizado na parte alta da cidade de Maceió, capital do estado de Alagoas. O bairro conta com cerca de 4.500 residências, entre casas e apartamentos. Embora nominado pelos seus residentes como um "bairro de classe média", Farol não pode ser comparável a um bairro de classe média de uma cidade grande, já que existe uma diferença estatisticamente significativa entre os rendimentos médios de seus habitantes. Entre estes, se encontram funcionários públicos, comerciantes e fazendeiros. O bairro do Farol é percebido como um dos mais seguros da cidade, tendo em vista o baixíssimo número de ocorrências de homicídio registrados na localidade (média de 2 por ano) (ALAGOAS, 2017).

Uma característica comum aos bairros analisados é a relativa proximidade com favelas ou (no caso maceioense) grotas. Nos três casos, as regiões limítrofes entre os bairros e os "aglomerados" são delimitadas por cercas ou barras de ferro. Em Laranjeiras, muros foram erguidos e guaridas instaladas para regular a entrada e a saída de pedestres e veículos. Com exceção de Laranjeiras, os bairros de Padre Eustáquio e Farol percebem rondas policiais com relativa constância.

\subsection{Percepções sobre a insegurança}

Apesar de serem contextos diferentes, em ambos os bairros pode-se identificar duas categorias principais de ameaça à segurança: I) aquelas ligadas à incidência de crimes, especificamente os crimes contra o patrimônio (roubos, furtos, etc.); e II) aqueles ligados à diferentes manifestações de desordem pública (sobretudo a prostituição e o consumo abusivo de álcool). Cada categoria tem manifestações específicas em cada bairro, como está detalhado na Tabela 1. Ambas as categorias são elementos que compõem a percepção de insegurança, de modo que ela não é entendida apenas em termos de vitimização. 
Entre as principais ameaças relacionadas com o crime, os moradores de ambos os bairros relatam principalmente o roubo de carro. Claro está a preocupação com a proteção do patrimônio no território do bairro. Da mesma forma, a desordem nos espaços públicos constitui uma grande preocupação dos vizinhos, embora suas manifestações se diferenciem em cada caso.

Tabela 1 - Ameaças à segurança segundo os entrevistados em Laranjeiras, Padre Eustáquio e Farol.

\begin{tabular}{llll}
\hline Tipos de ameaça & Laranjeiras & Padre Eustáquio & Farol \\
\hline \multirow{2}{*}{$\begin{array}{l}\text { Relacionadas à } \\
\text { criminalidade }\end{array}$} & Roubos de carro & Roubos de carro & Roubos de carro \\
& Roubos de celular & Roubos de celular & Saidinha de banco \\
& Roubo à casa & Roubo à casa & Furtos diversos \\
\hline \multirow{2}{*}{ Relacionadas à desordem } & Prostituição & Prostituição & Consumo de drogas \\
& Consumo de drogas & Consumo de drogas & Consumo de álcool \\
& Consumo de álcool & Consumo de álcool & Vandalismo \\
\hline
\end{tabular}

Fonte: elaborado pelo autor.

Tabela 2 - Origem das ameaças segundo os entrevistados em Laranjeiras, Padre Eustáquio e Farol.

\begin{tabular}{llll}
\hline & Laranjeiras & Padre Eustáquio & Farol \\
\hline \multirow{2}{*}{ Origem da ameaça } & $\begin{array}{l}\text { Moradores de outros } \\
\text { bairros }\end{array}$ & $\begin{array}{l}\text { Moradores de outros } \\
\text { bairros }\end{array}$ & $\begin{array}{l}\text { Moradores de outros } \\
\text { bairros }\end{array}$ \\
\hline
\end{tabular}

Fonte: elaborado pelo autor.

Em ambos os bairros, o consumo de álcool e drogas nos espaços públicos é considerado uma ameaça. No entanto, no Farol também existem ameaças ligadas às práticas de vandalismo. Em Laranjeiras e em Padre Eustáquio as ameaças estaria relacionadas com o aumento de bares e locais de prostituição. A origem dessas possíveis ameaças à segurança comunitária é unanimemente identificada pelos entrevistados em relação à imagem perigosa do seu entorno, os moradores das adjacências, dos bairros vizinhos, conforme resumido na Tabela 2. No bairro do Farol, por exemplo, a ameaça está fortemente relacionada aos moradores das grotas da Moenda e do Estrondo, associadas à forte presença do crime organizado e de gangues criminosas. Esse tipo de conhecimento influencia as formas de percepção e experimentação da cidade e de suas relações sociais. Os elementos que eles (os moradores do bairro do Farol) conjugam na construção do "perigo" e do "ator perigoso" se tornam estigmas para certos espaços e para aqueles que neles habitam.

No entanto, dada a densidade dos laços nesses bairros, a representação social sobre o ator perigoso também se estende ao estranho, que é definido por estar fora do bairro, o 
"outro" (GOFFMAN, 1970). Essas representações sobre outros vizinhos do bairro, assim como a percepção sobre de si mesmos, como vizinhos de maior status socioeconômico, compromete a interação nos espaços públicos, realimentando as imagens sobre o perigo e gerando um desejo de privação. Essas situações geram novas demandas de proteção e segurança, a fim de reduzir as potenciais ameaças ao "equilíbrio comunitário".

Nos três bairros estudados, a demanda por segurança está mais propriamente ligada ao controle do território: quem circula? De onde vêm e para onde vão? O que buscam no bairro? Residentes superestimam o poder de controlar o que acontece em sua vizinhança e buscam estabelecer uma clara diferenciação entre os que são "vizinhos" e os que são "forasteiros". Esse tipo de conduta, para além de contribuir com o reforço do estigma, traduzse não apenas em demandas informais de realocação do efetivo policial, mas ações judiciais, diligências encaminhadas ao Ministério Público.

Na medida em que o Estado não atende esse tipo de demanda, criam-se na própria comunidade novos mecanismos de proteção. A provisão de segurança cidadã para que o objetivo diminua em parte, o nível de insegurança dos vizinhos, tanto no nível objetivo como subjetivo. Isto é, não se trata apenas de garantir a integridade física e patrimonial dos habitantes de um bairro, mas também para diminuir suas percepções de insegurança. Os responsáveis pela provisão de segurança em nível local são, em primeiro lugar, as autoridades Estado, as Polícias Civil e Militar.

Nos bairros analisados, a confiança nessas instituições é fraca devido à imagem da ineficiência e aos recorrentes casos de corrupção nas polícias. No bairro de Padre Eustáquio, mais de $80 \%$ dos entrevistados afirmaram perceber a pouca ou nenhuma contribuição das polícias para a segurança do bairro, tal como como se apreende dos trechos destacados a seguir:

\footnotetext{
Moro nesse bairro há 15 anos. Nunca vi um policial chegar aqui pra expulsar esses maconheiros daqui. Nunca! Ligo, passo na delegacia e nada! Por esses dias, me juntei com os vizinhos pra saber quem tinha interesse em contratar um segurança particular pra vigiar a rua. Porque só assim. [...] eles [os policiais] não vêm aqui. Agora eu me pergunto o que eles andam fazendo. Todo ano tem concurso pra PM e até hoje eu não vi um aqui no bairro. Tão gastado o nosso dinheiro com o quê? É nosso dinheiro. É dinheiro público que paga os salários deles (Morador de Padre Eustáquio 03, em entrevista concedida ao autor).

São corruptos. Eu não acho, eu tenho certeza. [...] Eles ficam onde o pessoal paga pra eles ficarem. É um bom negócio no final das contas, não é não? É um segurança particular. E segurança particular por segurança particular, eu prefiro pagar um que eu sei que é honesto, que é formalizado e que vai trabalhar mesmo e exclusivamente. [...] O que falta na polícia é autoridade. (Moradora de Padre Eustáquio 12, em entrevista concedida ao autor).
} 
No bairro do Farol, a provisão da segurança pública também é deficiente, tal como declarado pelos moradores. Policiais que atuam na região reconhecem certa incapacidade institucional para patrulhar o bairro, mas também apontam incongruências em algumas demandas comunitárias:

\begin{abstract}
Para as patrulhas no bairro do Farol tem, formalmente, cinquenta policiais escalados. Vinte e cinco deles tão em 'dia de folga', como eles dizem, porque estão em guarda contínua, de plantão. Na maioria das vezes, dos vinte e cinco que restam, quinze são realocados pra outros bairros. Então no final das contas, temos dez policiais para o Farol, isso se ninguém precisar ir para as comissões-serviço externo. [...] Mas o pior de tudo é ter que se deparar com uma 'madame' que está olhando da janela do apartamento dois caras que ela achou estranho andando na rua dela e chamar a gente. (Policial, Transeunte do Farol 86, em entrevista concedida ao autor).
\end{abstract}

Em Laranjeiras, a imagem da polícia também é fortemente associada a casos de corrupção. Isso corresponde a uma percepção geral em nível nacional sobre as instituições de policiais na sociedade brasileira. A corrupção sistêmica no Brasil reflete não somente nas polícias, mas em todas as instituições responsáveis pela acusação e sanção do crime, tal como se percebe no trecho destacado a seguir:

Tem muita corrupção na polícia. Quando eles capturam um ladrão, sempre o liberam muito rápido. Se é um criminoso do colarinho branco, então... Está aí a nossa justiça que não me deixa mentir. [...] As autoridades às vezes respondem ao nosso chamado, às vezes não. Tudo depende de dinheiro. É por isso que as pessoas não confiam a polícia. Porque eles são corruptos (Morador de Laranjeiras 112, em entrevista concedida ao autor).

Em ambos os casos, é constante a sensação de que existe uma incapacidade do Estado em responder às demandas da vizinhança. Some-se isto à desconfiança nas instituições públicas responsáveis pelo provimento da segurança pública. O sentimento de frustração que resulta desse produto, conjugado às percepções de insegurança descrita nesses bairros, conduz a comunidade a procurar formas complementares de garantia da segurança em nível local.

\title{
4.3 Respostas vicinais: mecanismos comunitários de proteção
}

Dependendo das características e tradições de cada bairro, formas específicas de organização são estabelecidas para a provisão de segurança. Dois mecanismos diferentes podem ser observados: os cercamentos, no caso de Laranjeiras, e a vigilância local, ou rondas comunitárias, em Padre Eustáquio e Farol. Ambos os sistemas visam fornecer segurança à 
comunidade, muito embora os valores que justifiquem esses tipos de mecanismos para a manutenção da ordem estejam mais atrelados a uma estratégia de diferenciação e isolamento que compromete, inclusive, a própria convivência democrática nessas comunidades.

Tabela 3 - Características dos mecanismos comunitários de proteção em Laranjeiras, Padre Eustáquio e Farol.

\begin{tabular}{|c|c|c|c|}
\hline Características & Laranjeiras & Padre Eustáquio & Farol \\
\hline Objetivo & $\begin{array}{l}\text { Controle territorial e } \\
\text { social do bairro }\end{array}$ & $\begin{array}{l}\text { Controle social do } \\
\text { bairro e repressão de } \\
\text { delitos cometidos }\end{array}$ & $\begin{array}{l}\text { Controle social do } \\
\text { bairro }\end{array}$ \\
\hline Foco & $\begin{array}{l}\text { Prevenção situacional e } \\
\text { controle do território }\end{array}$ & $\begin{array}{l}\text { Prevenção situacional e } \\
\text { sanções (castigos } \\
\text { físicos ou serviços } \\
\text { comunitários) }\end{array}$ & Prevenção situacional \\
\hline Forma de funcionamento & $\begin{array}{l}\text { Vigilantes abrem e } \\
\text { fecham as cercas para a } \\
\text { passagem de veículos; } \\
\text { tratam de expulsar os } \\
\text { atores que rompem com } \\
\text { a ordem social do } \\
\text { bairro }\end{array}$ & $\begin{array}{l}\text { Vigilância noturna do } \\
\text { bairro por um grupo de } \\
\text { vigilantes ( } 10 \\
\text { aproximadamente), das } \\
21 \mathrm{~h} \text { às } 4 \mathrm{~h} \text { da manhã. } \\
\text { Em casos de } \\
\text { ocorrências graves, } \\
\text { contatam a polícia }\end{array}$ & $\begin{array}{l}\text { Vigilância noturna do } \\
\text { bairro por um grupo de } \\
\text { vigilantes ( } 10 \\
\text { aproximadamente), das } \\
21 \mathrm{~h} \text { às } 4 \mathrm{~h} \text { da manhã. } \\
\text { Em casos de } \\
\text { ocorrências graves, } \\
\text { contatam a polícia }\end{array}$ \\
\hline Grau de participação & $\begin{array}{l}\text { Baixo: os vizinhos } \\
\text { pagam uma taxa mensal } \\
\text { para a manutenção das } \\
\text { cercas e pagamento dos } \\
\text { vigilantes }\end{array}$ & $\begin{array}{l}\text { Alto: em alguns casos } \\
\text { os próprios vizinhos } \\
\text { saem para a fazer a } \\
\text { ronda junto com os } \\
\text { vigilantes }\end{array}$ & $\begin{array}{l}\text { Baixo: os vizinhos } \\
\text { pagam uma taxa mensal } \\
\text { para o pagamento dos } \\
\text { vigilantes }\end{array}$ \\
\hline
\end{tabular}

Fonte: elaborado pelo autor.

As semelhanças desses mecanismos residem principalmente em seu objetivo e foco: ambos procurar exercer algum tipo de controle territorial e social em seus respectivos bairros. No entanto, diferem suas formas de funcionamento e no grau de participação que eles exigem da comunidade. No caso do bairro de Laranjeiras, o controle territorial é feito a partir da instalação de grades que cobrem algumas das entradas e saídas do bairro (e da contratação de seguranças particulares no início dos anos 2000). Como resposta coletiva, a instalação das grades e sua manutenção denotam um grau significativo de organização social dos vizinhos, expressa mediante a contribuição econômica para manutenção e pagamento mensal dos vigilantes.

Para os moradores de Laranjeiras, a implementação das grades se fez necessária e relevante dado o consenso sobre a demanda de proteção contra crimes e eventos de desordem social, uma demanda fundamentada nas representações sobre os vizinhos ditos "perigosos". 
Nos bairros de Padre Eustáquio e Farol, as rondas urbanas promoveram a criação de conselhos comunitários de segurança, visando estender à comunidade as principais demandas em torno da segurança em nível local.

Em Padre Eustáquio, parece ser compartilhada a ideia de que "todo mundo tem que contribuir para a segurança pública" (Residente de Padre Eustáquio 23, em entrevista concedida ao autor). Essa visão garantiu à ronda urbana reconhecimento entre os moradores de outros bairros vizinhos e isso permitiu que eles estabelecessem canais de coordenação por toda a capital mineira.

Uma intervenção típica dos vigilantes é a cooperação com as polícias, apesar de recursos limitados e a disposição de autoridades:

\footnotetext{
Quando você pega alguém, um ladrão, um vândalo, você chama a PM e ela vêm com seus carros para levar o indivíduo para a delegacia. [...] Eles fazem toda a papelada [...], eles fazem as investigações e decidem se o detento permanecer sob custódia ou se eles liberam. Eles também continuam com o procedimento legal para trazer o criminoso para o juiz. Mas nem sempre há condições para coordenação e trabalho em conjunto (Morador de Padre Eustáquio 17, em entrevista concedida ao autor).
}

Além disso, uma vez que a ronda é composta por membros da comunidade, suas ações correspondem às prioridades da população. Mas a ronda também mantem um papel ativo na manutenção da ordem pública pelo controle da prostituição. Tanto as grades e guardas quanto as rondas urbanas respondem a preocupações locais e cumprem papéis específicos ligados ao controle do território e dos usos do espaço público.

Em certo sentido, o consenso social que emerge sobre o perigo e os níveis de organização para lidar com esse problema poderiam traduzir uma "eficácia coletiva". Contudo, os mecanismos específicos de ação nem sempre respeitam os direitos daqueles que não vêm desses bairros, e isso contradiz o "senso democrático" que, segundo Sampson (2012), caracteriza aquela mesma eficácia coletiva. Além disso, esses mecanismos nem sempre são eficazes no controle do crime, a despeito da virtual sensação de segurança que desperta na comunidade.

Esses mecanismos permitem que ambos os tipos de resposta gerem uma percepção de segurança tal como declarado pelos entrevistados. A despeito das representações que embasam a mobilização coletiva, esses mecanismos são percebidos como mais eficaz do que a resposta do Estado no provimento da segurança.

O controle social exercido por ambos os tipos de mecanismos obedece a certas normas e valores coletivamente compartilhados. Este "acordo" impede a desorganização 
social, entendida nos termos de Shaw e McKay (1969), e gera um efeito de vizinhança em relação a ela (SAMPSON et al., 2009). A existência de grades ou de vigilantes impactam na identificação dos moradores de bairros vizinhos em termos de atitudes e valores que porventura eles possam ter em comum e a rejeição sobre aqueles que não compartilham dessas atitudes e valores.

Esses mecanismos limitam os direitos daqueles que não pertencem ao bairro, que não formaram parte do consenso sobre os mecanismos de segurança. As grades restringem o tráfego de veículos e pedestres, forçando muitos a fazer desvios desnecessários. No caso das rondas, os "estranhos" estão sujeitos a um tipo de controle exercido por pessoas que, em tese, não têm poderes para fazê-lo.

O funcionamento desses mecanismos sem o devido o controle das autoridades se sujeita a excessos. Prova disso são alguns processos judiciais movidos contra vigilantes de Padre Eustáquio por sequestro e agressão. Para qualquer caso, o sistema de segurança no nível local consiste atualmente em dois tipos de fontes de prestação de serviços segurança: por um lado, as instituições do Estado com um mandato público para fornecer segurança e justiça (polícia, autoridades judiciárias, procuradores e agentes de segurança locais) e, por outro parte, a própria comunidade organizada, que assume de fato algumas funções na provisão da segurança.

Esta configuração aproxima-se daquilo que Garland (2001) descreve como um mercado de suprimentos segurança, que vem evoluindo no tempo, adquirindo uma forma mista de economia e estendendo os limites do controle formal para atores não estatais. Em nível local, os mecanismos vicinais de controle se tornam cada vez mais necessários para os residentes.

\section{CONSIDERAÇÕES FINAIS}

As percepções de insegurança nos bairros estudados incluem elementos contextuais relacionados ao crescimento urbano das cidades brasileiras nas últimas décadas. Esses elementos geraram novas dinâmicas caracterizadas pela presença de atores que reconfiguram os espaços e suas atividades econômicas. As percepções atuais de insegurança não estão apenas relacionadas à vitimização direta ou indireta, mas também com o medo que provem de fenômenos de desordem social. Ambos os elementos resultam na percepção geral sobre o perigo. Essas percepções também se alimentam da desconfiança nas autoridades. 
Existem diversas limitações relacionadas aos recursos e às capacidades institucionais, em diferentes níveis, para o provimento da segurança, bem como casos de corrupção e outros abusos, que geram descrédito generalizado sobre a população. Dada a baixa aprovação do trabalho dessas instituições e a urgência de algumas demandas, mecanismos aparecem inerentemente organizados pelos próprios cidadãos que procuram responder a uma necessidade por segurança, na sua dimensão objetiva e subjetiva.

Desta forma, diferentes formas emergem e estratégias de proteção individual ou coletiva, público ou privado, dentre as quais se encontram as rondas urbanas e as cercas de segurança nos bairros. Estes mecanismos procuram proteger o patrimônio dos vizinhos, bem como a sua integridade física e, por extensão, controlar o que acontece no bairro, que é entendido como propriedade privada comunitária. Como resultado, mesmo esses mecanismos não necessariamente conseguem controlar o crime, muito embora prestem a sensação de segurança aos indivíduos.

Embora ambos os mecanismos estejam organizados de diferentes maneiras, eles expressam percepções de insegurança relativamente similares. Eles traduzem, em parte, o que Sampson (et al., 2009) chamam de "eficácia coletiva". Mas por outro lado, esses mesmos mecanismos restringem liberdades, cerceiam direitos e, em alguns casos, se utiliza de violência para corresponder à insegurança, um tipo de "reação" que rompe com o senso democrático que é próprio do conceito de eficácia coletiva. As distintas configurações desses mecanismos, seja pelo exercício do controle social e manutenção da coerência social de uma vizinhança, seja pelo reforço do estigma e distanciamento, se inscrevem em uma demanda de reflexão sobre as dinâmicas que integram esses acordos comunitários sobre a segurança em diferentes contextos urbanos no Brasil.

\section{REFERÊNCIAS}

ALAGOAS. Secretaria de Segurança Pública. Boletim Anual da Estatística Criminal. 2017. Disponível em: <http://seguranca.al.gov.br/estatisticas/26/>. Acesso em: 14 out. 2018.

AVER, Ana. A relação iluminação pública e criminalidade. Especialize, v. 1, n. 4, p. 22-36, 2013.

BAUMAN, Zygmunt. Medo líquido. Rio de Janeiro: Zahar, 2008. 
BRISOLA, Elisa. Estado penal, criminalização da pobreza e Serviço Social. Revista SER Social, v. 14, n. 30, p. 127-154, 2012.

CAMPOS, C. H. et al. Cultura do estupro ou cultura antiestupro? Revista de Direito FGV, v. 14, n. 3, p. 981-1006, 2018.

DE PAULA, E. M. et al. A rotulação e o controle social como objeto de criminalização da juventude negra. In: JORNADA JURÍDICA DA FACULDADE EVANGÉLICA DE GOIANÉSIA, 1., 2018. Anais... Goianésia (GO): JJFACEG, 2018. p. 21-27.

DISSENHA, R. C.; JUNIOR, P. R. I. A internacionalização do poder punitivo: os riscos normativos e políticos da demanda por leis penais universais. Revista brasileira de ciências criminais, n. 147, p. 813-848, 2018.

GARLAND, David. La cultura del control. Crimen y orden social en la sociedad contemporánea. Madrid: Gedisa, 2001.

GOFFMAN, Erving. Strategic interaction. Philadelphia: University of Pennsylvania Press, 1970.

IBGE. Brasil em síntese. Cidades. 2015. Disponível em: <https://cidades.ibge.gov.br/> . Acesso em: 14 out. 2018.

LEFEBVRE, Henri. O direito à cidade. São Paulo: Moraes, 1991.

LEFEBVRE, Henri. A revolução urbana. Belo Horizonte: UFMG, 2002.

SAMPSON, R. et al. Shared beginnings, divergent lives. Boston: Harvard University Press, 2009.

SAMPSON, R. Great American city: Chicago and the enduring neighborhood effect. Chicago: University of Chicago Press, 2012. 
SANTOS, Milton. A urbanização brasileira. São Paulo: Hucitec, 1993.

SHAW, C.; MCKAY, H. Juvenile delinquency and urban areas: a study of rates of delinquency in relation to differential characteristics of local communities in American cities. Chicago: The University of Chicago Press, 1969.

STRAUSS, A.; CORBIN, J. M. Basics of qualitative research: Grounded theory procedures and techniques. San Jose (CA): Sage Publications, 1990.

TUAN, Yi-Fu. Paisagens do medo. São Paulo: Editora da Unesp, 2005.

VALLES, Miguel. Entrevistas cualitativas. CIS, 2007.

ZALUAR, Alba. Um debate disperso: violência e crime no Brasil da redemocratização. São Paulo em perspectiva, v. 13, n. 3, p. 3-17, 1999.

ZALUAR, A.; RIBEIRO, A. P. A. Teoria da eficácia coletiva e violência: o paradoxo do subúrbio carioca. Novos Estudos-CEBRAP, n. 84, p. 175-196, 2009.

\title{
INSECURITY AND COMMUNITY PROTECTION MECHANISMS IN BRAZILIAN CITIES
}

\begin{abstract}
The article discusses the perception of insecurity expressed by residents of neighborhoods in the cities of Maceió (AL), Rio de Janeiro (RJ) and Belo Horizonte (MG) and the respective community protection mechanisms implemented in order to manage the dilemma. The research compares three case studies based on the use of qualitative techniques. Fieldwork was carried out between March 2016 and December 2017. The neighborhoods were selected based on dissimilarity criteria in order to reflect on the different urban realities that currently exist in Brazil. Despite the different contexts on which the neighborhoods analyzed in this study are located, in both cases, it was possible to verify common characteristics that allowed the approach of the perceptions about insecurity and the visions about the provision of security, which sometimes contradict their own democratic coexistence in cities.
\end{abstract}


| Revista Transgressões: ciências criminais em debate, v. 7, junho de 2019

Keywords: Fear of crime. Perception of insecurity. Collective efficacy. Neighborhood effect. Community protection mechanisms. 